\title{
DIBUJOS PREPARATORIOS PARA EL GRUPO ESCULTÓRICO DE LOS CUATRO SANTOS DE SANTA MARIA DE GRACIA DE CARTAGENA
}

\author{
IGNACIO JosÉ GARCÍA ZAPATA ${ }^{1}$ \\ Universidad de Granada
}

\begin{abstract}
Este estudio se centra en unos dibujos del Museo de Bellas Artes de Valencia que han sido puestos en relación con el grupo escultórico de los Cuatro Santos de la parroquia de Santa María de Gracia de Cartagena, actualmente desaparecido. Palabras clave: Dibujos; Cuatro Santos; Santa María de Gracia; Cartagena.
\end{abstract}

\section{PREPARATORY DRAWINGS FOR THE SCULPTURE GROUP OF THE FOUR SAINTS OF SANTA MARIA DE GRACIA DE CARTAGENA}

This study focuses on some drawings from the Museum of Fine Arts in Valencia that have been put in relation to the sculptural group of the Four Saints of the parish of Santa María de Gracia in Cartagena, currently missing. Key words: Drawings; Four Saints; Santa María de Gracia; Cartagena.

Cómo citar este artículo / Citation: García Zapata, Ignacio José (2020) "Dibujos preparatorios para el grupo escultórico de los Cuatro Santos de Santa María de Gracia de Cartagena”. En: Archivo Español de Arte, vol. 93, núm. 372, Madrid, pp. 427-434. https://doi.org/10.3989/aearte.2020.29

Miguel Martí Esteve (1869-1939) fue un destacado coleccionista que reunió a lo largo de su vida un importante conjunto de obras de arte. A su muerte, esta colección fue adquirida por diferentes compradores, como Mateu y Fortuny de Barcelona y el Ayuntamiento de Valencia, que en 1951 se hizo con gran parte de la misma ${ }^{2}$. En 2016 salieron a la venta algunos de los dibujos que formaban parte de su legado, enriqueciendo el panorama del dibujo español de la Edad Moderna, especialmente valenciano, con obras atribuidas a Juan Conchillos y Falcó (1641-1711), Vicente Salvador Gómez (1637-1678), Mosén Domingo Saura (c. 1650-1715), Hipólito Rovira Meri (16931765), Ignacio Vergara Gimeno (1715-1776), José Vergara (1726-1799), José Camarón Bonanat (1731-1803), José Juan Camarón Meliá (1760-1819), Manuel Camarón Meliá (1763-1806), Rafael Esteve Vilella (1772-1847), Vicente López Portaña (1772-1850), Miguel Parra (1780-1846), Vicente Castelló Amat (1787-1860) y Luis Téllez Girón y Belloch (1810-1868)33.

De entre esta serie de dibujos destacan dos que han sido vinculados a uno de los escultores más relevantes del siglo XVIII, Ignacio Vergara $(1715-1776)^{4}$. Ambos, realizados a lápiz sobre

\footnotetext{
1 ignaciojosegz@ugr.es / ORCID iD: https://orcid.org/0000-0003-0559-7232

2 Gil Salinas, 1994: 58 y 66-68.

3 Espinós Díaz, 2016. Sobre el dibujo valenciano, véase: Pérez Sánchez, 1986: 421-441. Angulo y Pérez Sánchez, 1988. Espinós Díaz, 1984.

${ }^{4}$ Agradecer a David Gimilio Sanz, conservador de arte valenciano del Museo de Bellas Artes de Valencia, por su disponibilidad y consejos, así como a los doctores Dña. Adela Espinós Díaz, D. Manuel Pérez Sánchez, D. José Alberto Fernández Sánchez y D. Álvaro Pascual Chenel. Asimismo a Santiago Rodríguez López.
} 


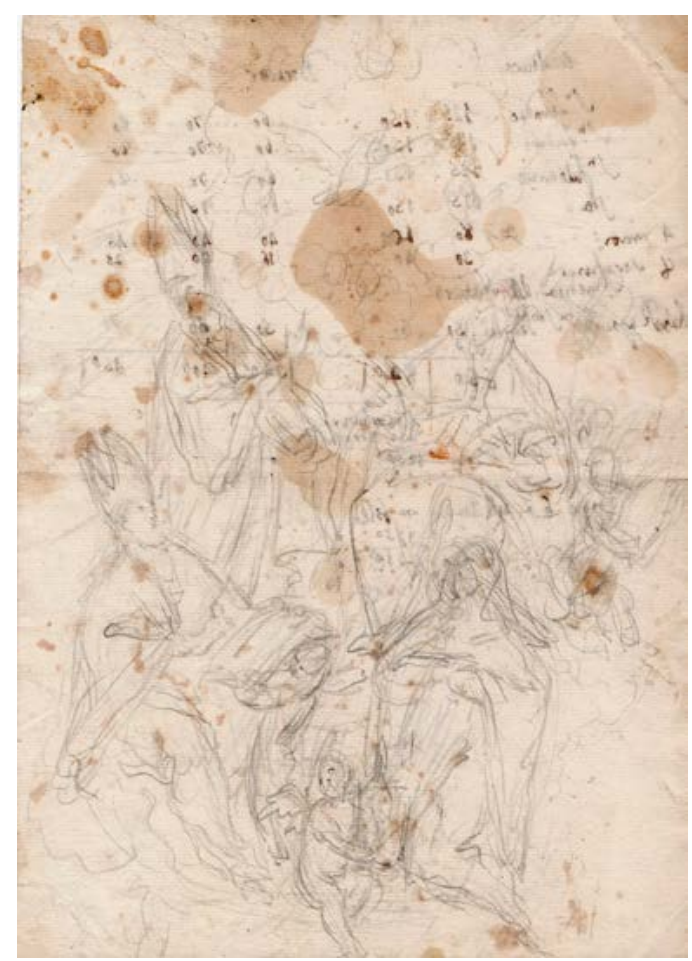

Fig. 1. Cuatro Santos de Cartagena,

$2^{\circ}$ mitad siglo XVIII, Valencia, Museo de Bellas Artes. Inv. No. 5/2018. Imagen: Museo de Bellas Artes de Valencia.

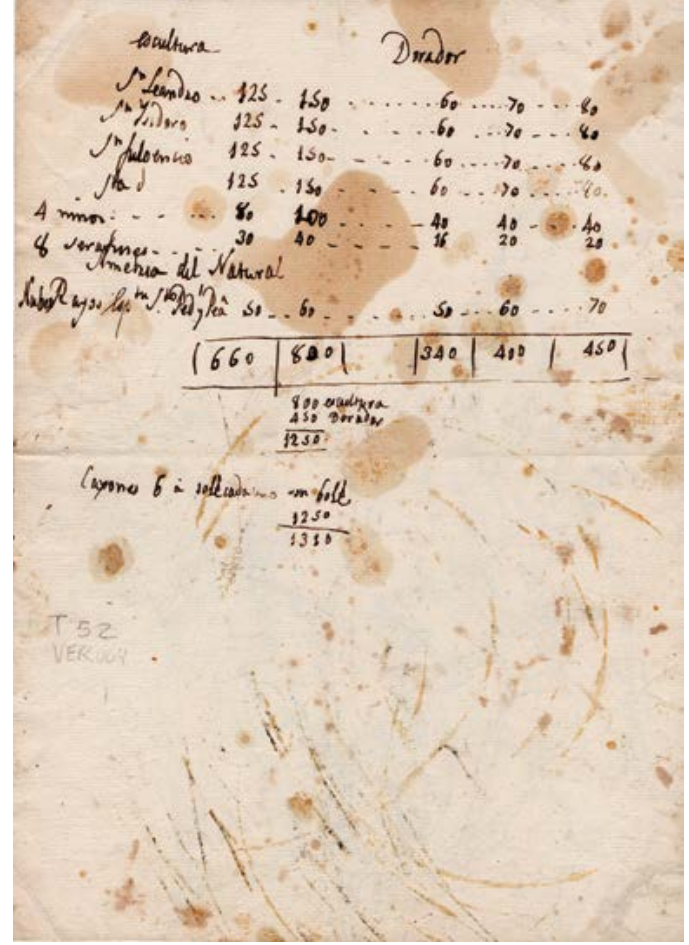

Fig. 2. Cuatro Santos de Cartagena (detalle cuentas), $2^{\circ}$ mitad siglo XVIII, Valencia, Museo de Bellas Artes. Inv. No. 5/2018 (verso). Imagen: Museo de Bellas Artes de Valencia.

papel verjurado, se corresponden con una misma composición para un grupo escultórico de los Cuatro Santos de Cartagena: San Fulgencio, San Leandro, San Isidoro y Santa Florentina. El tratamiento más esquemático de uno de ellos, frente al trabajo mucho más elaborado del segundo, hace pensar que el primero corresponda a un primer planteamiento que más adelante fue definido con mayor precisión por su autor. No obstante, en los dos casos se mantiene una composición muy similar que tan solo se ve alterada en la disposición de alguna figura y en el cambio de lugar de determinados angelitos que completan el trabajo. Así, en el primero de ellos, queda ya marcada la estructura de la obra en la que Santa Florentina y uno de los santos obispos aparecen en primer término, ella arrodillada y con las manos entrelazadas, y él sentado y en actitud de escribir sobre un libro que es sostenido por un angelito, junto al que se encuentra otro, a los pies de la santa. Por encima de estas imágenes se ubican los dos hermanos restantes, uno de pie y el otro, el que está detrás de la santa, sentado, ambos sosteniendo un libro cerrado en sus manos. Detrás de este último surge un angelito que sostiene una mitra, ya que este santo no la tiene puesta, como sí sucede con los otros dos hermanos [fig. 1]. Las cuatro imágenes dirigen su mirada hacia la paloma del Espíritu Santo que está situada en el centro de un cúmulo de nubes y rayos dispuesto en la parte superior ${ }^{5}$. En el verso de este dibujo se encuentra además una relación de cuentas por cada una de las hechuras y el dorado de las esculturas de los cuatro santos, cuatro niños, ocho serafines y de las nubes y rayos, es decir, más imágenes de las que finalmente se debieron realizar, lo que podría indicar que dicho dibujo fue finalmente descartado [fig. 2] ${ }^{6}$.

\footnotetext{
5 Inv. No. 5/2018. Lápiz negro sobre papel verjurado; $305 \mathrm{~mm}$ x $213 \mathrm{~mm}$, Museo de Bellas Artes de Valencia

${ }^{6}$ Inv. No. 5/2018 (verso). Lápiz negro sobre papel verjurado; $305 \mathrm{~mm}$ x $213 \mathrm{~mm}$, Museo de Bellas Artes de Valencia
} 
Fig. 3. Cuatro Santos de Cartagena, $2^{\circ}$ mitad siglo

XVIII, Valencia, Museo de Bellas Artes. Inv. No. 6/2018. Imagen: Museo de Bellas Artes de Valencia.

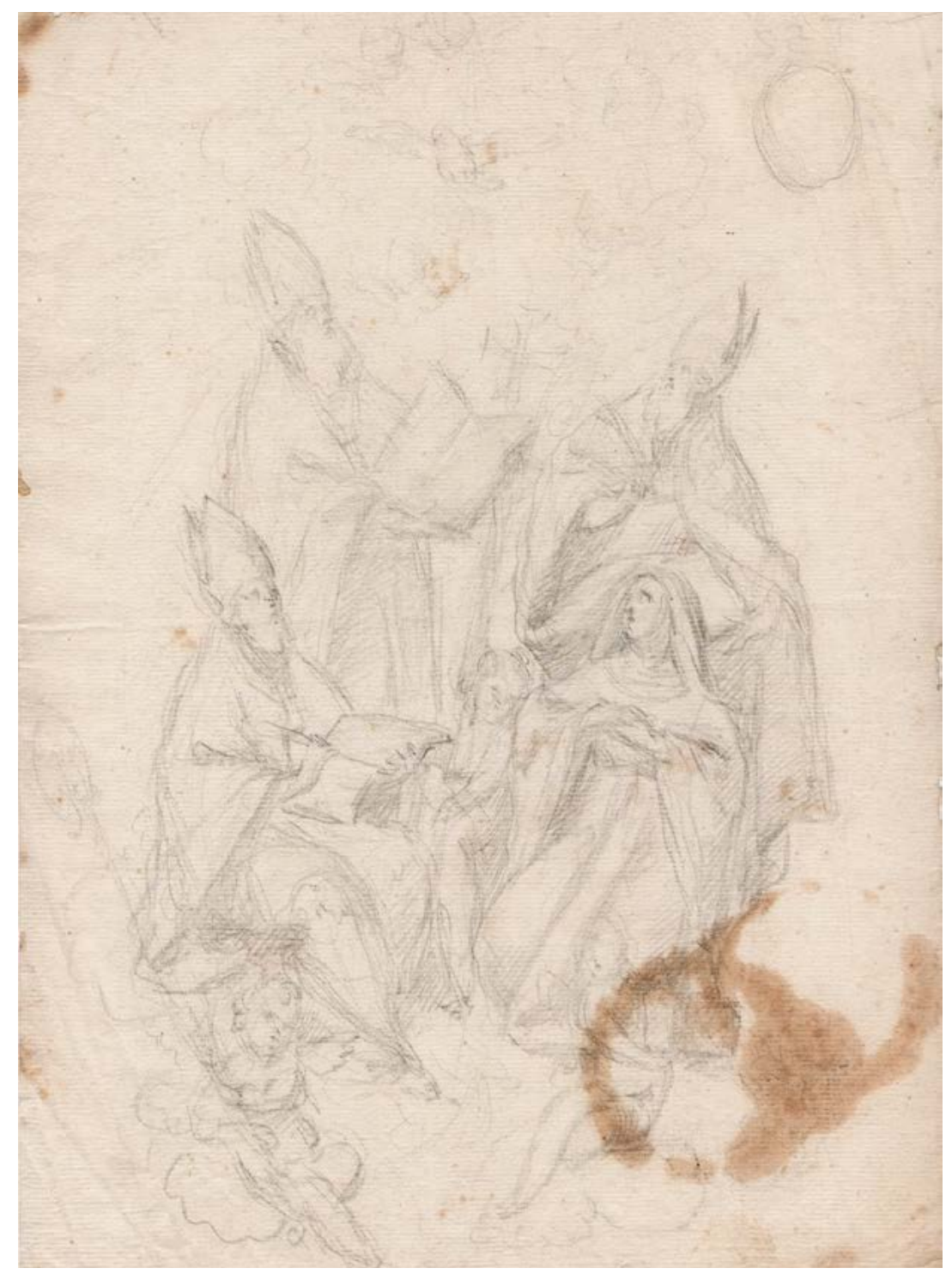

El segundo de los dibujos corresponde claramente a un perfeccionamiento del antecedente, sobre todo por cómo el trazado del dibujo está mucho más elaborado y es más preciso, con las imágenes más definidas. Además, los rasgos faciales son más elocuentes y tanto las vestiduras como los diferentes atributos están mucho más precisados. Se trata de un dibujo con un detalle mucho mayor, por lo que cabe pensar que se corresponda con la versión final, en la que se introducen ciertas modificaciones con respecto al diseño inicial propuesto. Las cuatro imágenes principales se encuentran en el mismo lugar, pero ahora las dos delanteras están sentadas y las dos traseras de pie. A ello se suma el cambio de posición de los ángeles, situándose uno en medio de los cuatro santos, y los otros dos a los pies de la primera pareja de santos portando diferentes atributos. En la parte superior sigue manteniéndose la paloma del Espíritu Santo entre nubes y rayos. En definitiva, en este dibujo se confiere al conjunto una mayor simetría en lo que respecta a la disposición más equilibrada de cada una de las figuras [fig. 3] $]^{7}$.

\footnotetext{
7 Inv. No. 6/2018. Lápiz negro sobre papel verjurado; 305 mm x 213 mm, Museo de Bellas Artes de Valencia
} 
Hasta el momento tan solo se había apuntado que estos dibujos estarían relacionados con algún proyecto realizado para la ciudad de Cartagena, ya que la representación de los cuatro santos hermanos fue muy habitual en el Reino de Murcia y en toda su diócesis, pues eran hijos del duque Severiano, gobernador visigodo de la provincia cartaginense en el siglo $\mathrm{VI}^{8}$. Todos ellos emprendieron una vida dedicada a la defensa de la Iglesia contra el arrianismo. San Leandro y San Isidoro fueron arzobispos de Sevilla, mientras que San Fulgencio lo fue de Écija y Cartagena, y Santa Florentina fue abadesa y fundadora de numerosos conventos ${ }^{9}$. Evidentemente, la fama alcanzada por ellos, los puestos ocupados, sus virtudes y sus acciones, les convirtieron en referencia y orgullo de su diócesis de nacimiento. Tras la Contrarreforma y la promoción que esta hizo de los santos, la diócesis de Cartagena exaltó sus figuras como medio para manifestar la importancia de la iglesia local. Para ello fueron fundamentales las diferentes acciones realizadas por el obispo Sancho Dávila (1546-1625), quien fundó el nuevo Seminario Mayor de San Fulgencio, lo nombró patrón de la diócesis y consiguió la aprobación de Felipe II (1527-1598) para que se enviaran a la Catedral de Murcia las reliquias de San Fulgencio y Santa Florentina ${ }^{10}$. A partir de entonces se inició un intenso programa artístico en el que los cuatro santos eran los protagonistas; así, sus imágenes se dispusieron en los grandes proyectos artísticos de la diócesis, como en lo alto de la torre de la Catedral de Murcia, en la nueva custodia del Corpus que hizo el platero toledano Antonio Pérez de Montalto (¿?-1685) o en las esculturas que para Santa María la Vieja de Cartagena hizo Francisco Salzillo (1707-1783) ${ }^{11}$.

El culto a los cuatro santos conllevó que en 1779 se fundara en la nueva parroquia de Santa María de Gracia de Cartagena la Hermandad de los Cuatro Santos, que vio superadas sus expectativas y tuvo que incrementar su número de hermanos para dar cabida a todos aquellos que deseaban formar parte de la misma. En ese momento se acordó construir una capilla que contó con la ayuda económica de la élite local, como demuestran las aportaciones económicas del general Borja, el conde Fernán-Núñez y José Segarra, así como de otros ilustres personajes de la ciudad ${ }^{12}$. La construcción de dicha capilla comenzó en mayo de 1786, momento en el que se acordó situarla en la cabecera del templo para señalar así su relevancia, finalizando su obra pocos meses después ${ }^{13}$. Una antigua fotografía, realizada antes de la destrucción del templo y de su patrimonio en $1936^{14}$, permite identificar sin ningún tipo de duda los dibujos de los cuatros santos señalados con el grupo escultórico que se dispuso en la capilla de esta hermandad, aunque el resultado final de la obra difiere ligeramente del reflejado en los dibujos [fig. $4]^{15}$. En primer lugar, la composición es más abierta: en los dibujos se aprecia una disposición rectangular mientras que en la obra escultórica hay una tendencia hacia el triángulo, con las dos figuras de la parte inferior abiertas hacia los extremos y giradas sobre sí mismas. Igualmente, el orden y la posición de las figuras ha variado, ya que la parte superior es ocupada por las imágenes de San Fulgencio y Santa Florentina, otorgando así mayor protagonismo a estos dos santos, cuya vinculación con la diócesis era mucho mayor. Por otro lado, el trono de nubes es más grande y de él surgen cuatro querubines en la parte más baja, situándose otros dos en el centro de toda la obra.

Como se ha indicado al inicio, estos dibujos fueron atribuidos al escultor Ignacio Vergara, dado que las figuras comparten ciertas características propias de la obra de este artista valencia-

\footnotetext{
${ }^{8}$ Esta vinculación con la ciudad portuaria ya fue apuntada por la profesora Espinós Díaz, véase: Espinós Díaz, $2016, n^{\circ} 8$ y 9 .

9 Herraiz, 1764. Rodríguez Herrera, 1996: 76-86.

10 Dávila y Toledo, 1611. Olivares Terol, 2006: 411-424. Lozano Pérez, 1993: 7-33.

11 García Zapata, (en prensa).

12 Martínez Rizo, 1894: 29-30 y 187-188. Maestre-De San Juan Pelegrín, 2014: 95-112.

13 Archivo Municipal de Cartagena, CH00314, Oficio de la ciudad sobre el acuerdo para señalar sitio en la iglesia de Santa María de Gracia para la capilla de los Cuatro Santos. Cartagena, 30 de mayo de 1786.

14 Paredes Oltra, 2009: 50.

15 Instituto del Patrimonio Cultural de España, Ministerio de Cultura y Deporte, Fototeca del Patrimonio Histórico Español, [Cartagena] Iglesia de Santa María de Gracia. Capilla de los Cuatro Santos, hijos de la ciudad: San Fulgencio, San Leandro, San Isidro y Santa Florentina, António Passaporte, Inv. No. LOTY-05774, 1930.
} 


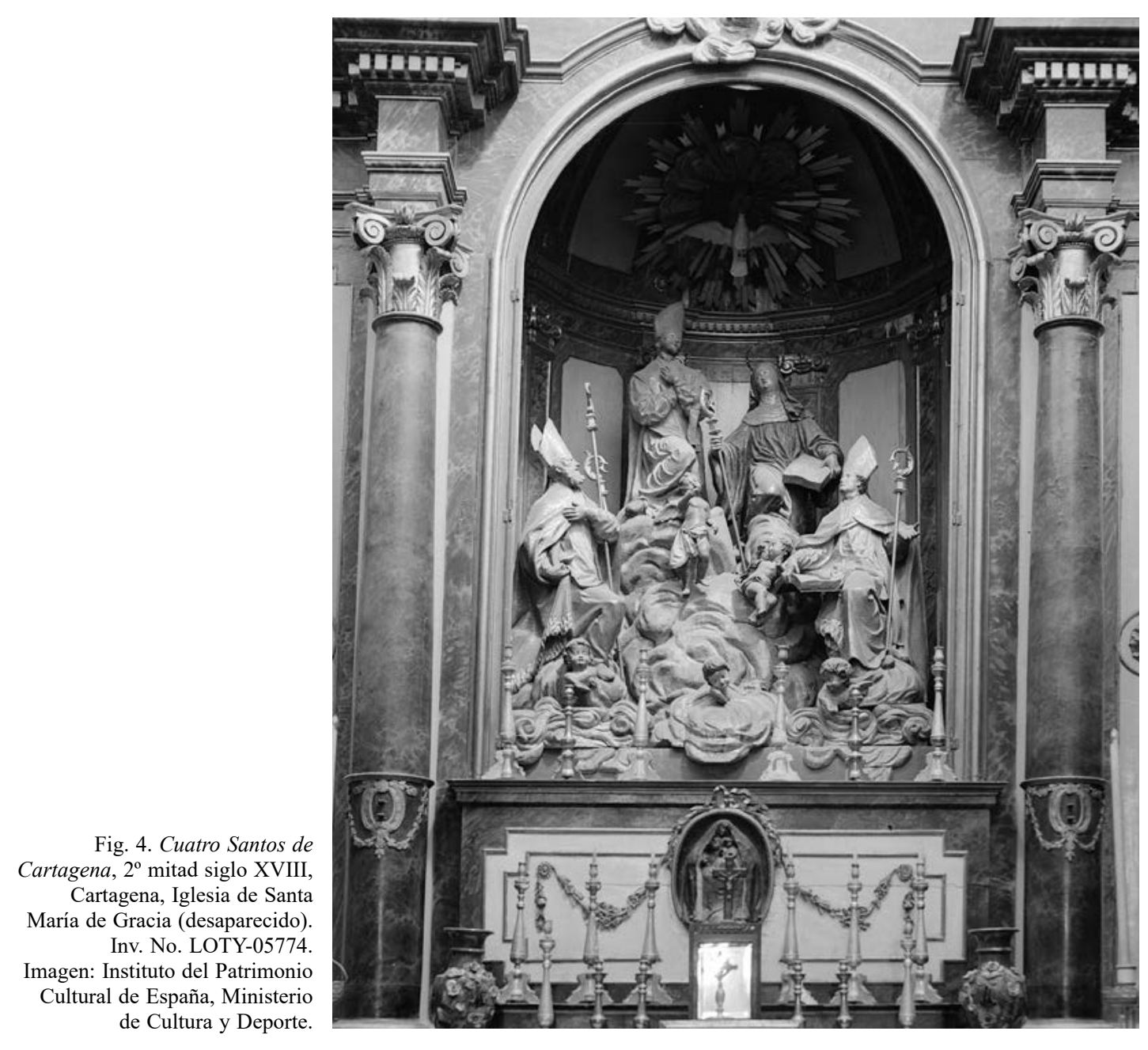

no ${ }^{16}$. Sin embargo, se conocen solo unos pocos dibujos de Vergara con los que poder llevar a cabo una comparación que sostenga esta atribución. Entre ellos, en el Museo de Bellas Artes de Valencia se hallan algunos estudios del cuerpo humano relacionados con su tarea como docente en la academia. En lo que respecta a la imagen religiosa, en el mismo museo se encuentra un dibujo preparatorio del relieve de la portada principal de la Catedral de Valencia, y en el Museo del Prado se halla un dibujo de la Inmaculada Concepción, realizado en lápiz sobre papel blanco, en el que se incorpora una leyenda que indica que fue realizada en madera por Vergara para Cádiz. Con todo, si se comparan estos dibujos con los de los cuatro santos parecen advertirse ciertas diferencias que abren la posibilidad de que estos últimos dibujos se correspondan en realidad a la mano de otro artista.

Asimismo, como ya se ha señalado, la capilla de los cuatro santos fue construida hacia 1786 , una década después de la muerte de Vergara, por lo que las esculturas, de hacerse específicamente para este espacio, como todo hace indicar, no pudieron ser realizadas por Vergara, ya falleci$\mathrm{do}^{17}$. Por tanto, el conjunto escultórico debió ejecutarse sobre ese año o entre 1779, año de fun-

16 Sobre el escultor Ignacio Vergara, véase: Buchón Cuevas, 2006; 2015.

17 D. Elías Tormo, en su itinerario por Cartagena, al hacer mención al conjunto de los cuatro santos de la parroquia de Santa María de Gracia no dio ninguna atribución y fechó el grupo escultórico a mediados del siglo XVIII, véase: Tormo, 1923: 373. 


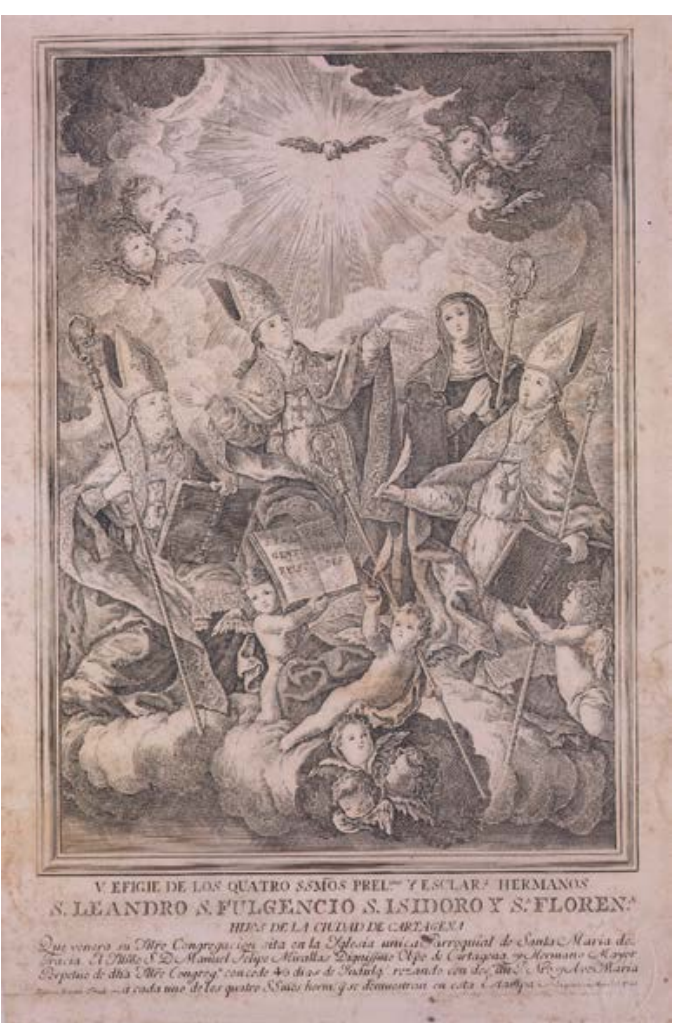

Fig. 5. Fernando Martín, Apoteosis de los Santos de Cartagena, 1786. Imagen: Depósito Académico Digital de la Universidad de Navarra.

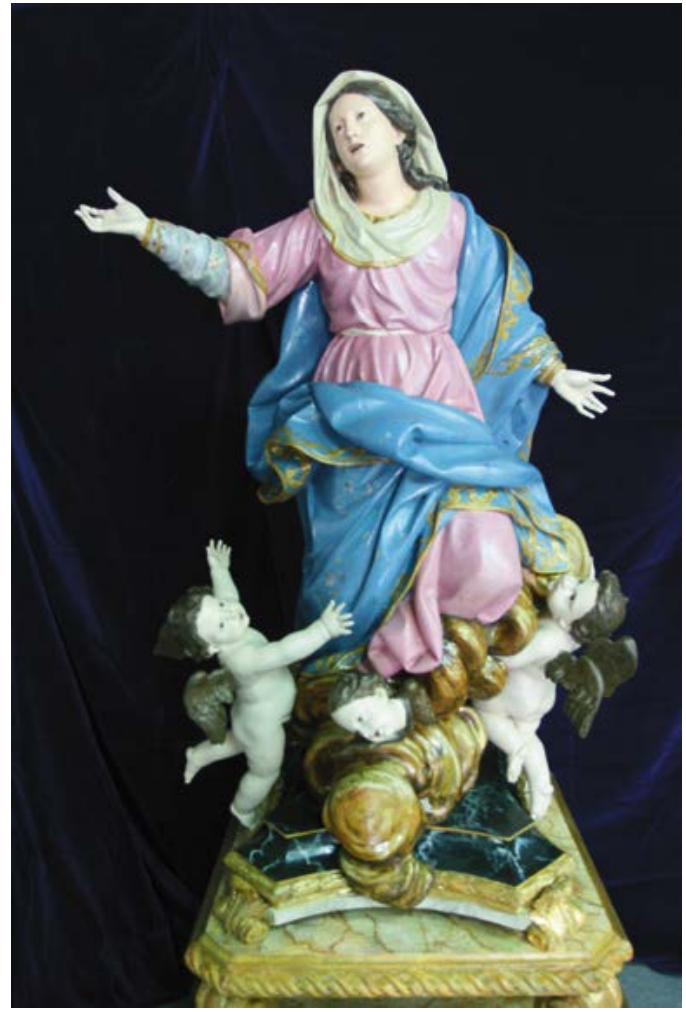

Fig. 6. José Esteve Bonet, Virgen de los Remedios, 1786, Cartagena, Cementerio de Santa Lucia. Imagen: Ayuntamiento de Cartagena.

dación de la hermandad, y 1786, cuando se publicó un grabado con la imagen de este conjunto escultórico, seguramente con motivo del fin de las obras de la capilla y la colocación de las esculturas [fig. 5] ${ }^{18}$. También hay que tener en cuenta que hasta 1777 no se trasladó el culto a la parroquia de Santa María de Gracia.

De este modo, tal vez cabría revisar dicha atribución y fijar la atención en uno de sus discípulos, José Esteve Bonet (1741-1802), quien se convirtió en uno de los escultores más destacados del levante español tras la muerte de Vergara, llegando a ser nombrado escultor de cámara honorario de Carlos IV (1748-1819) tras hacer el Belén para el infante Carlos de Borbón (1788$1855)^{19}$. De hecho, individualmente las imágenes tienen ciertos rasgos neoclásicos que Esteve Bonet puso en práctica en la escultura valenciana de su tiempo, a través de líneas más finas y elegantes propias de esa escultura de finales del Setecientos, en la que el academismo fue adquiriendo un mayor protagonismo e irradiando toda la producción artística de estas últimas décadas. Esto se hace mucho más evidente en el caso de los rostros, en los que hay una dulzura y delicadeza en su tratamiento en línea con la escultura que predominó a partir de entonces y, por tanto, diversa a otras esculturas de santos obispos realizadas por Vergara, como puede apreciarse en el Santo Tomás de Villanueva del Museo de la Ciudad de Valencia. Por otro lado, la composición triangular del conjunto, con los santos dispuestos en dos niveles y con la paloma del Espíritu Santo como ángulo superior, recuerda a algunas de las disposiciones que usaron los plateros

18 Pamplona, Depósito Académico Digital de la Universidad de Navarra, inv. no. EST.301.929 (grabado).

19 Sobre el escultor José Esteve Bonet, véase: Martí Mallol, 1867. Igual Úbeda, 1971. Para una aproximación a las últimas investigaciones acerca de este escultor, véase: Delicado Martínez, 2017: 317-332. Belso Delgado, 2017: 225-242. 
valencianos del siglo XVIII en sus custodias, como puede verse en la que Bernardo Quinzá hizo para la Colegiata de Játiva, platero con el que Esteve Bonet había colaborado para la custodia que Quinzá había hecho para Cartagena. Con todo, compositivamente se trata de una obra influenciada por el estilo de Vergara.

Más allá de estas cuestiones formales hay que valorar los vínculos que Esteve Bonet mantuvo a lo largo de su vida con la ciudad de Cartagena, para la que hizo diversos trabajos, desde que entre 1766 y 1767 realizó unos niños para la mencionada custodia de Quinzá20, hasta que en 1799 se desplazó a Cartagena, donde llegó a estar once días para disponer el grupo escultórico de la Santísima Trinidad situado en el mismo templo de Santa María de Gracia $^{21}$. Este conjunto estaba formado por las figuras del Padre Eterno, Jesucristo y el Espíritu Santo sobre un gran trono de nubes entre ángeles y serafines, es decir, semejante al grupo de los cuatro santos, y fue encargado por la corporación de Comerciantes Catalanes de Cartagena, que en 1779 obtuvo el permiso para realizar su capilla en la cabecera del templo, en la nave norte, mientras que la nave sur quedó para la Hermandad de los Cuatro Santos ${ }^{22}$. Dicho viaje quedó reflejado en su Libro de la Verdad, en el que tomaba nota de sus trabajos y de otros aspectos relacionados con el mismo, donde aprovechó para señalar su paso por Murcia, Orihuela y Alicante, ciudades donde entró en contacto con la obra de Salzillo ${ }^{23}$. Sin embargo, en este libro no aparece referenciado el conjunto de los cuatro santos, al igual que tampoco se encuentra anotada la escultura de la Virgen de los Remedios del Cementerio de Santa Lucía de Cartagena, que está fechada y firmada por Esteve Bonet en 1786, lo que demuestra que no todas sus obras fueron referenciadas en ese libro y, lo que es más importante, cómo ese año, cuando se concluyó la capilla de los cuatro santos y se publicó el grabado, el escultor valenciano estaba trabajando en Cartagena [fig. 6]. Finalmente, no hay que olvidar que el coleccionista Martí Esteve era descendiente de Esteve Bonet, lo que hace más directa la relación y la posibilidad de que los dibujos fueran realizados por este escultor.

La comparación estilística no es posible dado que hasta la fecha no se han documentado otros dibujos de Esteve Bonet, aunque en el mismo lote de dibujos expuestos en 2016 se incluía un dibujo de San Antonio que se relacionó con este escultor, en base a que en su Libro de la Verdad aparece la realización en varias ocasiones de esculturas de este santo ${ }^{24}$. Sí aparece en esta relación de Esteve Bonet la ejecución en 1767 de un conjunto formado por la Virgen del Rosario flanqueada por las imágenes de Santa Catalina de Siena y Santo Domingo de Guzmán. Un dibujo con estas mismas imágenes formaba también parte de la colección de Martí Esteve, atribuido en esta ocasión a Vergara, aunque habría que vincularlo más bien a la obra de Esteve Bonet ${ }^{25}$.

En definitiva, ambos dibujos del Museo de Bellas Artes de Valencia se corresponden con un boceto preliminar para el grupo escultórico identificado de los Cuatro Santos de la parroquia de Santa María de Gracia de Cartagena, que hay que vincular a la órbita de Esteve Bonet, escultor valenciano relacionado con la ciudad portuaria y con el mencionado templo.

\section{BIBLIOGRAFÍA}

Angulo, Diego / Pérez Sánchez, Alfonso (1988): A corpus of Spanish drawings. Valencia 1600-1700. London: Harvey Miller.

Baquero Almansa, Andrés (1980): Los profesores de las Bellas Artes Murcianos: con una introducción histórica. Murcia: Ayuntamiento de Murcia.

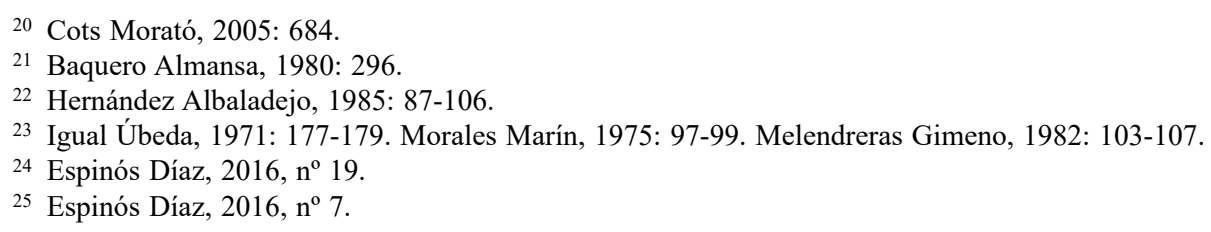


Belso Delgado, Marina (2017): “Algunas consideraciones sobre la clientela y los encargos del escultor José Esteve Bonet para la provincia de Alicante”. En: Cañestro Donoso, Alejandro (eds.): Estudios de escultura en Europa. Alicante: Instituto Alicantino Juan Gil-Albert, pp. 225-242.

Buchón Cuevas, Ana María (2006): Ignacio Vergara y la escultura de su tiempo en Valencia. Valencia: Generalitat Valenciana.

Buchón Cuevas, Ana María (2015): Ignacio Vergara en el tricentenario de su nacimiento, 1715-2015, exh. cat. Valencia: Consorcio de Museo de la Comunitat Valenciana.

Cots Morató, Francisco de Paula (2005): Los plateros valencianos en la Edad Moderna (siglos XVII-XIX): Repertorio biográfico. Valencia: Universidad de Valencia.

Dávila y Toledo, Sancho (1611): De la veneración que se debe a los cuerpos de los Santos y a sus Reliquias y de la singular con que se ha de adorar el Cuerpo de Nuestro Señor en el Santísimo Sacramento. Madrid.

Delicado Martínez, Francisco Javier (2017): “El escultor José Esteve Bonet y sus obras en Yecla (Región de Murcia). Una revisión a la luz de nuevas aportaciones documentales". En: Cañestro Donoso, Alejandro (ed.): Estudios de escultura en Europa. Alicante: Instituto Alicantino Juan Gil-Albert, pp. 317-332.

Espinós Díaz, Adela (1984): Museo de Bellas Artes de Valencia. Catálogo de dibujos (Siglo XVIII). Madrid: Ministerio de Cultura.

Espinós Díaz, Adela (2016): La colección Miguel Martí Esteve. Dibujos valencianos del siglo XVIII al XIX, exh. cat. Barcelona: Palau Antiguitats.

García Zapata, Ignacio José (en prensa): "La imagen de una diócesis. Los Cuatro Santos de Cartagena y su presencia en el arte". En: Carthaginensia, 71.

Gil Salinas, Rafael (1994): Arte y coleccionismo privado en Valencia del siglo XVIII a nuestros días. Valencia: Ediciones Alfonso El Magnànim.

Herraiz, Antonio (1764): Los quatro misticos ríos del paraíso de la Iglesia, quatro hermanos santos, Leandro, Fulgencio, Isidoro y Florentina, Honra de Cartagena, Gloria de España y Esmalte de la Fe Catholica. Breve compendio de sus vidas, y virtudes, coronado con una Devota Novena, para incentivo de la Devocion Christiana, Valencia.

Hernández Albaladejo, Elías (1985): "El templo de Santa María de Gracia de Cartagena: un proyecto inacabado". En: Imafronte, 1, pp. 87-106.

Igual Úbeda, Antonio (1971): José Esteve Bonet. Imaginero valenciano del siglo XVIII. Vida y obras. Valencia: Instituto Alfonso el Magnánimo.

Lozano Pérez, José María (1993): "Dos aspectos de la proyección del Concilio de Trento en la Diócesis de Cartagena: Culto a San Fulgencio y Fundación del Seminario". En: Scripta Fulgentina, 5-6, pp. 7-33.

Maestre-De San Juan Pelegrín, Federico (2014): "Las Cofradías de Cartagena fundadas en sedes regidas por el clero secular durante la Edad Moderna". En: Murgetana, 130, pp. 95-112.

Martí Mallol, José Vicente (1867): Biografía de D. José Esteve Bonet, escultor valenciano. Castellón: Imprenta y Librería de Rovira Hermanos.

Martínez Rizo, Isidoro (1894): Fechas y fechos de Cartagena. Cartagena.

Melendreras Gimeno, José Luis (1982): "Escultores valencianos en Murcia, durante los siglos XVIII y XIX”. En: Archivo de arte valenciano, 63, pp. 103-107.

Morales Marín, José Luis (1975): “Esteve Bonet y Francisco Salzillo”. En: Archivo de arte valenciano, 46, pp. 97-99.

Olivares Terol, María José (2006): "Un ejemplo de aplicación del Concilio de Trento en la diócesis de Cartagena-Murcia el seminario de San Fulgencio". En: Carthaginensia, 42, pp. 411-424.

Paredes Oltra, Encarnación (2009): "Iglesia de Santa María de Gracia en Cartagena. Análisis histórico, constructivo y de patologías". En: XX Jornadas de Patrimonio Cultural de la Región de Murcia. Murcia: Tres Fronteras, pp. 49-63.

Pérez Sánchez, Alfonso (1986): Historia del dibujo en España de la Edad Media a Goya. Madrid.

Rodríguez Herrera, Isidoro (1996): "Cuatro Santos de Cartagena. La Mariología de San Leandro". En: Scripta Fulgentina, 11, pp. 76-86.

Tormo, Elías (1923): Levante (Provincias valencianas y murcianas). Madrid: Calpe.

Fecha de recepción: $14-\mathrm{V}-2020$

Fecha de aceptación: 09-VII-2020 